\title{
EFSUMB Guidelines on Interventional Ultrasound (INVUS),
} Part II

\section{Diagnostic Ultrasound-Guided Interventional Procedures (Short Version)}

\section{EFSUMB Leitlinien interventioneller Ultraschall (INVUS), Teil II Diagnostische Ultraschall-gestützte Interventionen (Kurzversion)}

Authors

P. S. Sidhu' ${ }^{1}$, K. Brabrand ${ }^{2}$, V. Cantisani ${ }^{3}$, J. M. Correas ${ }^{4}$, X. W. Cui ${ }^{5,6}$, M. D’Onofrio ${ }^{7}$, M. Essig ${ }^{8}$, S. Freeman ${ }^{9}$, O. H. Gilja ${ }^{10}$, N. Gritzmann ${ }^{11}$, R. F. Havre' ${ }^{12}$, A. Ignee ${ }^{5}$, C. Jenssen ${ }^{13}$, A. Kabaalioğlu ${ }^{14}$, T. Lorentzen ${ }^{15}$, M. Mohaupt ${ }^{16}$, C. Nicolau ${ }^{17}$, C. P. Nolsøe ${ }^{15}$, D. Nürnberg ${ }^{18}$, M. Radzina ${ }^{19}$, A. Saftoiu ${ }^{20,21}$, C. Serra ${ }^{22}$, Z. Spârchez ${ }^{23}$, I. Sporea ${ }^{24}$, C. F. Dietrich ${ }^{5,6}$

Affiliations Affiliation addresses are listed at the end of the article.

Key words
guideline
biopsy
ultrasound
aspiration
CT
MRI
needle
catheter
cancer
transplant
adrenal
liver
kidney
pancreas
lymph node
gastrointestinal tract
retroperitoneal
spleen

Bibliography

Dol http://dx.doi.org/

10.1055/s-0035-1566760

Published online: 2015

Ultraschall in Med 2015; 36:

566-580 @ Georg Thieme

Verlag KG Stuttgart · New York .

ISSN 0172-4614

Correspondence

Prof. Dr. med. Christoph

F. Dietrich

Medizinische Klinik 2, Caritas

Krankenhaus Bad Mergentheim Uhlandstr. 7

D-97980 Bad Mergentheim

Germany

Tel.: ++ 49/(0)7931/58-22 01/

2200

Fax: ++ 49/(0)7931/582290

Christoph.dietrich@ckbm.de

\section{Abstract \\ $\nabla$}

This is the second part of the series on interventional ultrasound guidelines of the Federation of Societies for Ultrasound in Medicine and Biology (EFSUMB). It deals with the diagnostic interventional procedure. General points are discussed which are pertinent to all patients, followed by organ-specific imaging that will allow the correct pathway and planning for the interventional procedure. This will allow for the appropriate imaging workup for each individual interventional procedure (Long version/ short version; the long version is published online).

\section{Introduction}

$\nabla$

This is the second of three guidelines (parts I - III) within the framework of the European Federation of Societies for Ultrasound in Medicine and Biology (EFSUMB) Guidelines on Interventional Ultrasound (INVUS) describing percutaneous ultrasound (US)-guided diagnostic and therapeutic abdominal interventions. Part II gives evidencebased recommendations for the safe and efficient performance of US-guided diagnostic interventions based on the available evidence at the time of manuscript preparation. It is preceded by guidelines on general principles and necessities of INVUS (part I) [1] and followed by US-guided therapeutic abdominal interventions (part III) [2]. Methods of guideline development are described in the introduction to the EFSUMB Guidelines on Interventional Ultrasound (INVUS) [3]. Levels of Evidence (LoE) and Grades of Recommendations (GoR) have been assigned according to the Oxford Centre for Evidence-based Medicine criteria (March 2009 edition) [http://www.cebm. net/oxford-centre-evidence-based-medicine-levels-evidence-march-2009].

\section{Zusammenfassung \\ $\nabla$}

Der zweite Teil der Serie von Leitlinien der European Federation of Societies for Ultrasound in Medicine and Biology (EFSUMB) zur interventionellen Sonografie beschreibt die Vorbereitung, Indikationen, Durchführung und Nachsorge ultraschallgestützter diagnostischer Interventionen am Abdomen. Nach Darstellung allgemeiner, für alle Patienten gültiger Voraussetzungen werden organbezogen Bildgebung, Planung und Ablauf der verschiedenen diagnostischen Interventionen dargestellt (Langversion/ Kurzversion; die Langversion ist online publiziert).

\section{General Principles of Diagnosis for Ultra- sound-Guided Interventional Procedures} $\nabla$

Diagnostic interventional ultrasound (INVUS) procedures are efficient, minimally invasive techniques with the purpose of acquiring a diagnosis. Ultrasound (US) is the ideal imaging modality to guide interventional procedures with several advantages: the absence of radiation and lack of potentially nephrogenic contrast agents, US is inexpensive and real-time imaging ensures the visualization of needles, thus improving diagnostic accuracy with a reduction of complications [4-6]. Details are given in part I [1].

\section{Essential Rules}

- There must be a clearly defined indication for the diagnostic procedure and the risk should not outweigh the potential benefits.

- Accurate planning for INVUS procedures is essential to avoid complications. The operator should select the image guidance and interventional access pathway with the lowest risk.

- INVUS procedures require informed consent.

- Normal coagulation indices and platelet count are necessary to reduce bleeding risk [7]. There 
is no consensus regarding the threshold values that preclude interventional procedures, but platelet count $<50000 / \mu \mathrm{L}$ and Quick time $<50 \%$ are commonly used indices [8]. In patients with $<50000$ platelets, prior to a high-risk procedure (e.g. liver or kidney biopsy, nephrostomy, complex radiofrequency ablation (RFA)), a transfusion of platelets is necessary [9]. For patients undergoing a moderate risk procedure (e.g. chemoembolization, venous interventions, chest, lung and intraabdominal biopsy, drainage, direct RFA, spine procedures) or low bleeding risk procedures (e.g. thoracocentesis, paracentesis, superficial abscess drainage, venography), a platelet transfusion is recommended [7]. The International Normalized Ratio (INR) value should be corrected to $<2.0$ prior to low-risk procedures and $<1.5$ prior to moderate to high-risk procedures. In patients with a Quick time $<50 \%$, vitamin K or administration of fresh plasma is recommended before the procedure. In most abdominal INVUS procedures, it is recommended to discontinue antiplatelet therapy in the peri-procedural period.

- INVUS procedures that have an increased risk of septic complications (e.g. prostate biopsy) should include prophylactic antimicrobials to reduce post-INVUS procedure infection.

- The use of sedation has to be considered in non-cooperative patients or when performing an INVUS procedure where an immobilized patient is crucial. All personnel performing any interventional procedure must observe aseptic conditions, and the puncture site must also be sterile.

- Whenever possible, the use of continuous US guidance is recommended to reduce the risk of complications. The use of contrast-enhanced US (CEUS) or fusion techniques may be helpful in large tumors with necrosis, or in tumors that are invisible or poorly visible on grayscale US to improve the accuracy in obtaining adequate tissue samples [10 - 12].

- Diagnostic interventional procedures can often safely transgress the stomach and small or large bowel with fine needles (22 gauge) [13].

- Correct identification and suitable transportation of the tissue samples in an appropriate medium are essential.

- The most common complication of the INVUS procedure is puncture site pain requiring simple analgesia. A major complication is hemorrhage [14] and normal coagulation indices do not preclude bleeding complications.

- Following a diagnostic INVUS procedure, the patient should remain under medical observation to detect early complications.

\section{Multidisciplinary decision}

The multidisciplinary setting should be the standard to discuss INVUS procedures to confirm the necessity of the procedure, possible alternatives and complications.

\section{What defines the probability of performing an INVUS procedure?}

- Availability of a safe needle path governs the performance of an INVUS procedure.

- The target structure should be visible during the procedure.

- Risk of bleeding should be taken into account.

- Patient cooperation is needed.

Fine needle biopsy or aspiration

Different sample types may be obtained either with a fine needle biopsy (FNB) or FNA depending on indication and local protocol; cytology is often adequate but insufficient when tissue architecture is essential, e. g. lymphoma.

\section{Specimen preparation}

The preparation and care of specimens depend on the local laboratory services, proximity to the procedure room, and availability of specialist technicians.

\section{Cytology specimen preparation}

Perform 1 - 2 passes. For each needle pass performed, prepare $\geq 2$ good quality slides, with fixation according to the standard of the local cytology laboratory.

\section{Histology specimen preparation}

Specimens should be submitted in an adequate amount of $10 \%$ neutral-buffered formalin fixative. The volume ratio of fixative to specimen size is very important for proper preservation of the tissue, i.e., a minimum of at least twice the volume of fixative as tissue is required.

\section{Microbiology specimens}

A strict aseptic collection technique is necessary to avoid contamination. It is essential to obtain sufficient material for cultures [15] and perform the appropriate culture depending on the clinical suspicion.

\section{Follow-up imaging}

Immediate post-procedural imaging is not routinely recommended. Patients should be observed following a standard protocol in a dedicated unit with appropriately trained staff. Standard procedure-specific post-biopsy observation sheets which highlight the management of suspected complications should be available [16].

\section{Recommendation 1}

Informed consent is mandatory in all ultrasound-guided interventional procedures with variation of forms as indicated in general ethical and national legislative documents (LoE 5, GoR D). Strong consensus (100\%).

\section{Recommendation 2}

Specific assessment of bleeding risk and considerations for the use of blood products or other hemostatic agents must be individualized to the patient. The INR value should be corrected to $<2.0$ prior to low-risk procedures and $<1.5$ in moderate to high-risk procedures. In patients with $<50000$ platelets, a transfusion of platelets is necessary prior to high bleeding risk procedures (LoE 2a, GoR C). Strong consensus (100\%).

\section{Recommendation 3}

Repeat biopsy is recommended when there is an inconclusive result or insufficient or non-diagnostic material. Critical evaluation of the first attempt is mandatory before considering an optimized repeated procedure (LoE 5, GoR D). Broad agreement (94\%). 


\section{Recommendation 4}

Adequate material for a microbiology specimen is essential, and should be collected in sterile tubes, with correct labelling to assure appropriate analysis (LoE 5, GoR D). Strong consensus $(100 \%)$.

\section{Recommendation 5}

Post-procedural care is essential to detect complications and should be part of appropriate patient management (LoE 2b, GoR B). Strong consensus (100\%).

\section{Liver}

$\nabla$

\section{Diffuse liver disease}

Liver biopsy (LB) for diffuse liver disease can be performed percutaneously, laparoscopically or by a transjugular approach.

\section{Percutaneous liver biopsy}

Indications for percutaneous liver biopsy

1. Evaluation of chronic liver diseases for staging and grading

2. Confirmation of diagnosis and prognosis

3. Evaluation of abnormal liver function tests

4. Diagnosis of cholestatic liver disease

5. Evaluation of infiltrative or granulomatous disease

6. Post-liver transplantation to evaluate and manage rejection

7. Evaluation of unexplained jaundice or suspected drug reactions

Contraindications for percutaneous liver biopsy

1. Patient refusal or uncooperative patient

2. Ascites

3. Infection of the hepatic bed

4. Severe coagulopathy

5. Platelet count $<70000 / \mu \mathrm{L}$, transfusion is recommended [17].

\section{Antithrombotic agents}

Antithrombotic agents should be stopped or substituted before INVUS procedures, ensuring optimal risk/benefit ratio for the patient.

\section{Post Liver Biopsy}

After LB, a period of four hours of observation, including measurement of pulse and blood pressure, is recommended [17]. Performing LB in an outpatient setting is standard practice.

\section{Technical aspects of a liver biopsy}

Important aspects of percutaneous LB include:

1. LB under US guidance is safer than a blind biopsy [18 - 21];

2. LB specimen size is related to the diameter of the needle; a 15 -18-gauge needle will provide sufficient portal tracts for histological diagnosis [22];

3. Operator experience has an influence on the quality of the sample [22, 23];

4. An optimal specimen should be $\geq 25 \mathrm{~mm}$ long and include $\geq 11$ portal tracts [18].

\section{Complications}

Complications following LB performed by experienced operators are low [24]. The main complications following percutaneous LB are: pain, vasovagal reactions, liver hematoma (symptomatic or asymptomatic), hemoperitoneum, pneumothorax, hemobilia, bile leakage, organ perforation (gallbladder, colon) and arteriovenous fistula.

\section{Laparoscopic liver biopsy}

This can be performed during a laparoscopic procedure (e. g. cholecystectomy) or during a diagnostic laparoscopy. Diagnostic laparoscopy has the advantage that it visualizes the superior and inferior surfaces of the liver and enables guidance of the biopsy.

\section{Transjugular liver biopsy}

This is performed in patients at high risk of bleeding and in whom percutaneous LB is hazardous. The technique is complex and an experienced operator is needed. The quality of the specimen is essential for diagnosis. The rate of complications after this procedure is $1-20 \%$, with a mortality of $0.1-0.5 \%$ [25].

\section{Focal liver lesions}

Despite the evolution of imaging methods, such as CEUS, contrast-enhanced computed tomography (CE-CT), contrast-enhanced magnetic resonance imaging (CE-MRI), as well as the availability of tissue elastography for focal liver lesion (FLL) assessment, histological evaluation is often required. FLL biopsy is performed under guidance (usually by US).

\section{Indications for FLL biopsy}

- Diagnosis not established on any imaging

- Lesion immune-histochemical analysis needed for therapy

- Histological assessment is needed for a therapeutic decision (e. g. hepatocellular carcinoma vs. cholangiocarcinoma).

\section{Contraindications for FLL biopsy}

Identical as for percutaneous LB.

\section{Technique}

The lesion is biopsied under US guidance, always passing through healthy liver, to avoid bleeding. The needle size used to biopsy an FLL can vary from thin needles 23 - 20 gauge for FNA to large needles 18 - 15 gauge for core biopsy.

\section{Complications of FLL biopsy}

Complications include shoulder pain, bleeding, tumor seeding, organ perforation (gallbladder, colon) and sepsis. The incidence of complications varies depending on operator experience, needle type and tumor location. More frequent complications include: pain $(<20 \%)$ and liver hematoma $(1-20 \%)$. The following other complications are seldom encountered: intraperitoneal bleeding $(<1 \%)$, pneumothorax $(<1 \%)$, death $(0.0083-0.03 \%)$ $[26,27]$. The risk of malignant seeding during biopsy is rare $(0.003-0.009 \%)[28,29]$.

\section{Recommendation 6}

Liver biopsy is associated with a low rate of complications ( $\mathrm{LoE}$ 2b, GoR B). Broad agreement (94\%). 


\section{Recommendation 7}

The discontinuation of acetyl salicylic acid (aspirin) is not necessary when performing a liver biopsy (LoE 2b, GoR B). Broad agreement (81\%).

\section{Recommendation 8}

Liver parenchymal biopsy should be performed with ultrasound, either guided or assisted (LoE 2b, GoR C). Broad agreement (88\%).

\section{Spleen}

\section{Introduction}

Focal lesions of the spleen are rarely encountered but can be difficult to characterize. The risks of splenic biopsy are lower than generally thought and can be undertaken safely in most patients while achieving high levels of diagnostic accuracy. Percutaneous splenic biopsy carries significantly less risk than diagnostic splenectomy $[30,31]$.

\section{Background}

Focal lesions of the spleen are uncommon, encountered in only $0.2-1.0 \%$ of abdominal US examinations [32].

\section{Sonographic features}

Focal lesions may be solid, cystic or mixed in nature. Although certain focal lesions have distinctive US features, definitive characterization is often impossible based on the clinical history, laboratory tests and imaging characteristics.

\section{Contrast-enhanced ultrasound}

The use of CEUS can be very helpful in identifying and characterizing focal splenic lesions, as summarized in previous guidelines [33].

\section{Indications}

The most common indications for biopsy are:

- Focal lesion in a patient with known or suspected lymphoma

- Focal lesion in a patient with a known extrasplenic malignancy

- Focal lesions in immunocompromised patients

- Pyrexia of unknown origin with splenic abnormality

- Cystic lesion where there is concern of malignancy or abscess

\section{Contraindications}

Contraindications to biopsy include:

- Uncorrectable coagulopathy

- Lack of a safe biopsy pathway

- Uncooperative patient

- Hemodynamic instability

- Severe cardiopulmonary compromise

\section{Materials and Technical Issues}

\section{Pre-biopsy planning}

Prior to biopsy all imaging studies should be reviewed to identify the safest route of access. In patients with imaging abnormalities at multiple sites, a non-splenic biopsy site is usually preferred. A minimum platelet count of $50000-70000 / \mu \mathrm{L}$, INR $<1.2-1.6$ and APTT $20-33 \mathrm{sec}$ are required $[34,35]$.

\section{Biopsy technique}

Biopsy is usually possible with local anesthesia. Subcostal puncture minimizes the risk of pleural transgression but higher punctures may be necessary to target specific lesions. Hemorrhage is minimized by targeting a peripheral lesion [35-37]. Lesions close to the splenic hilum are a relative contra-indication to biopsy.

Fine needle aspiration cytology versus core needle biopsy Both fine needle aspiration cytology (FNAC) and core needle biopsy (CNB) can be used [36, 38 - 43]. A meta-analysis involving 741 splenic biopsies in 639 patients [34] found that $95 \%$ provided sufficient material for analysis, with an overall sensitivity of $87.0 \%$ and specificity of $96.4 \%$. The results of FNB and CNB were similar except for lymphoma where CNB gave statistically superior results [44]. CNB needle size should be 18 gauge or smaller to minimize the risk of hemorrhagic complications $[34,45,46]$. The complication rate of 18-gauge biopsies does not appear to be greater than with smaller needle sizes and provides greater diagnostic accuracy [47].

\section{Sample preparation}

CNB samples are usually sent to the laboratory in formalin solution. Several FNAC aspirates are optimal for cytology prepared as 2-4 smeared air-dried slides and an aspirate in cytology collection fluid to allow preparation of a micro-pellet.

\section{Post-procedure care}

Post-procedure the patient should be carefully observed for a minimum of 4 hours. Discharge is possible at this stage [35, 37] provided that the patient is asymptomatic and discharged to a responsible caregiver.

\section{Complications}

The most common major complications are hemorrhage and splenic rupture. Rarely splenic biopsy may result in a pneumothorax. A meta-analysis of 859 biopsies in 741 patients calculated an overall complication rate of $4.2 \%$ and a major complication rate of $2.2 \%$ [34]. No reports of needle tract tumor seeding from splenic tumors were identified.

\section{Recommendation 9}

Focal lesions of the spleen are uncommon; definitive diagnosis based on imaging appearances may not always be possible and biopsy may be considered if a definitive diagnosis is required (LoE 3b, GoR C). Strong consensus (100\%).

\section{Recommendation 10}

Ultrasound is the imaging modality of choice for most splenic biopsy procedures (LoE 5, GoR D). Strong consensus (100\%).

\section{Recommendation 11}

Biopsy of focal splenic lesions has high levels of diagnostic accuracy. Overall, core needle biopsy is slightly superior to fine needle aspiration for cytology particularly if lymphoma is suspected (LoE 2a, GoR B). Strong consensus (97\%). 


\section{Recommendation 12}

The complications of splenic biopsy are predominantly due to bleeding, with the complication rate of core needle biopsy being slightly greater than fine needle aspiration for cytology but lower than splenectomy (LoE 2a, GoR B). Strong consensus (100\%).

\section{Recommendation 13}

For core needle biopsy a needle size of $18 \mathrm{G}$ or smaller should be used to minimize the risk of splenic bleeding (LoE 2a, GoR B). Strong consensus (100\%).

\section{Pancreas}

Biopsy of focal pancreatic lesions

Solid pancreatic lesion

Patients with a ductal adenocarcinoma characterized as resectable on imaging should have no preoperative sampling performed (avoiding false-negative results) with surgical referral instituted [48-52]. Histopathological confirmation is necessary for inoperable pancreatic cancer and for patients who are unsuitable for surgery prior to non-surgical neoadjuvant treatments [53]. FNA or CNB can be performed to determine the Ki-67 value of neuroendocrine neoplasms for prognosis.

\section{Cystic pancreatic lesion}

Percutaneous sampling of cystic pancreatic lesions has limited supporting evidence and endoscopic ultrasound (EUS)-guided sampling is performed in these cases [54]. EUS-FNA cytology is more accurate than fluid analysis in the differentiation of benign and malignant cystic pancreatic lesions. The combination of cytology and fluid analysis is the best method for malignant lesions $[54,55]$. Cystic neoplasms requiring surgery with typical imaging appearances do not require EUS-FNA before resection; most pancreatic cystic tumors should be resected without the need for cystic fluid analysis [56].

\section{Imaging and sampling accuracy}

Focal pancreatic lesions (FPL) are initially identified on transabdominal US examinations. The addition of elastography may evaluate the stiffness of the lesion. A distinction between solid and cystic masses is crucial $[57,58]$. Further evaluation of solid pancreatic lesions relies on CECT [59]. Better results for the diagnosis of ductal adenocarcinoma can be obtained when CT is combined with CEUS [60]. A percutaneous US-guided approach is preferred for minimal invasiveness, low cost, and duration of the procedure, and allows appropriate cytology assessment of solid lesions [61 -63]. FNA is superior to core-needle or open biopsy. Cystic lesions that require pathological diagnosis are sampled via EUS [64-68]. The accuracy of percutaneous US-FNA of pancreatic masses reaches $99.4 \%$ [61, 62, $69-73]$. A sensitivity of $89 \%$, a specificity of $98 \%$, a positive predictive value of $99 \%$, and a negative predictive value of $74 \%$, for an overall diagnostic accuracy of $91 \%$, have been reported [63]. The accuracy of percutaneous sampling varies depending on the lesion position: 93 - 94\% for bodytail lesions, $83-84 \%$ for head lesions $[72,74]$.

\section{Indications}

- Characterization of a solid unresectable pancreatic mass.

- Differential diagnosis between neoplasm and focal inflammatory conditions.

- Suspicion of an uncommon entity (i.e., metastases, lymphoma), even if resectable, which could be treated non-operatively.

- Ki-67 "quantification" for the prognosis of neuroendocrine neoplasms [75].

- Cystic lesions that are undefined or suspicious for malignancy after MR imaging evaluation, even if an endoscopic approach is preferable to address this issue.

\section{Contraindications}

- Coagulation disorders are absolute contraindications to pancreatic diagnostic interventional procedures.

- Patient refusal of any therapy is a contraindication for biopsy.

\section{Ultrasound biopsy procedure}

US evaluation of a lesion includes B-mode and Doppler imaging to evaluate content and identify the safe and most productive biopsy route, with CEUS aiding positioning in viable vascularized areas.

\section{Complications}

Percutaneous US-guided FNA complications are rare [62]. No major complications were reported in a multicenter study [63]. US guidance has lower complication rates as compared to CT guidance: $1.7-5.0 \%$ versus $2.4-19.0 \%[72-74,76,77]$. The risk of tumor seeding is reported in both percutaneous and endoscopic procedures [78, 79].

\section{Follow-up imaging}

At the end of a percutaneous intervention, a complete US evaluation of the abdomen should be performed.

\section{Pancreas parenchyma biopsy}

Indications and contraindications

Diagnostic intervention is not required for the diagnosis of diffuse pancreatic diseases (i. e., acute and chronic pancreatitis) except for the diffuse form of autoimmune pancreatitis (AIP).

\section{Diagnostic puncture for pancreatitis-associated fluid}

Fine needle aspiration culture of pancreatic fluid collections is useful if the diagnosis is uncertain allowing optimized antibacterial therapy, but is not routinely indicated, as sampling has a $25 \%$ false-negative result and rarely leads to an alteration in clinical management $[80,81]$.

\section{Recommendation 14}

In patients with a resectable pancreatic mass with typical imaging aspect of ductal adenocarcinoma, a preoperative sample should not be performed and patients should be directly referred for surgical evaluation (LoE $2 b$, GoR B). Strong consensus $(100 \%)$.

\section{Recommendation 15}

Resectable pancreatic masses with atypical features at imaging should be referred for EUS and EUS-guided sampling (LoE 3b, GoR A). Strong consensus (97\%). 


\section{Recommendation 16}

Borderline resectable pancreatic masses in candidates for neoadjuvant treatment should be referred for EUS and EUSguided sampling (LoE 2b; GoR C). Strong consensus (100\%).

\section{Recommendation 17}

Unresectable locally advanced pancreatic solid masses should be referred for diagnostic biopsy in candidates for oncological treatment (LoE 2b, GoR B). Strong consensus (100\%).

\section{Recommendation 18}

Unresectable locally advanced pancreatic masses should be evaluated for percutaneous ultrasound-guided biopsy. If a percutaneous route is not feasible, EUS should be considered (LoE 5, GoR D). Strong consensus (100\%).

\section{Recommendation 19}

Percutaneous US guidance of the pancreas should be preferred to CT owing to the lower complication rates (LoE $2 b$, GoR B). Broad agreement (83\%).

\section{Recommendation 20}

Biopsy should be targeted to the suspected liver metastases for diagnosis and staging (LoE 5, GoR D). Strong consensus (100\%).

\section{Recommendation 21}

Sampling of cystic pancreatic masses should be performed under EUS guidance (LoE 5, GoR D). Strong consensus (100\%).

\section{Recommendation 22}

Cystic pancreatic masses typical at imaging and requiring surgery should not be sampled before resection (LoE 5, GoR D). Strong consensus (96\%).

\section{Kidney}

\section{Introduction}

Renal biopsy will be performed in both the native and transplant kidney [82].

\section{Imaging modalities}

Alternative imaging options should be considered as appropriate if US does not provide the required information. For drainage of an abscess or the collecting system and biopsy of the renal parenchyma in the assessment of renal impairment, US is adequate.

\section{Multidisciplinary decision}

The decision for INVUS related to tumor treatment should be made in an interdisciplinary tumor meeting.
What defines the possibility of performing an INVUS procedure?

The INVUS procedures for diagnostic workup are limited by absolute and relative contraindications. INVUS is available at a reasonable cost and in low resource settings, yet requires investigators experienced in the procedure [4].

\section{Diffuse renal disease}

Percutaneous renal biopsy has become the gold standard for the diagnosis and classification of diffuse renal diseases, in the absence of a major contraindication, particularly when specific treatment can be initiated [83].

\section{Indications and contraindications}

Indications

There is no generally accepted standard protocol for selecting patients for renal biopsy. The decision for renal biopsy is largely made by weighing therapeutic benefit against potential complications.

\section{Contraindications}

The most common contraindications for percutaneous renal biopsy are mentioned elsewhere [83].

\section{Pathology}

The biopsy report for non-neoplastic kidney diseases represents a complex integration of clinical data with light microscopy, immunofluorescence, and other (electron) microscopic findings. A renal biopsy specimen should always be interpreted within the context of the clinical presentation and laboratory findings.

\section{Ultrasound guidance}

Real-time US is superior to the "blind" approach (using US for localization only) with a higher diagnostic yield (100\% vs. $84 \%$ ) and a lower complication rate [5].

\section{Biopsy technique}

The choice of biopsy needle is largely one of individual preference. Most studies have been performed with semi-automated biopsy needles with a size of 14-18 gauge in order to ensure a sufficient number of glomeruli [84-88].

How many passes?

It is recommended to obtain two core renal biopsies from the lower pole of the left kidney in the absence of local contraindications, such as polar atrophy, arteriovenous fistula or cyst.

Needle size

Renal biopsy produces the highest diagnostic yield with more glomeruli per core biopsy using 14-gauge Tru-cut needles compared to 16- and 18-gauge needles without a difference in complication rates [84-88].

Fine needle aspiration cytology versus core needle biopsy There is no role for FNAC in the evaluation of diffuse renal disease.

Post-procedural care

After biopsy, an observation time of 6 hours is thought sufficient but up to 24 hours may be considered in patients with a higher risk of bleeding. 
Out- or inpatient

There is a trend to perform biopsies in outpatient clinics [89]. Post-procedural care is recommended for at least 8-12 hours, since $80-85 \%$ complications occur within 8 hours [90 - 93].

\section{Complications}

High blood pressure, female gender, younger age, abnormal coagulation (prolonged bleeding time) and both acute and chronic renal failure are associated with a higher complication rate [94, 95].

\section{Focal renal lesions}

The differentiation between benign and malignant renal lesions is of upmost importance. Diagnostic biopsy success is reported between $75-100 \%$ and has improved with a significant reduction of indeterminate biopsies (around 10\%) [96-98].

\section{Indications}

Renal lesion biopsy is indicated when management will change under the following circumstances:

- Small renal masses that are indeterminate on imaging

- Known extrarenal malignancy

- Candidates for active surveillance or local ablative techniques

- Metastatic disease to select the optimal systemic therapy when the renal tumor is the most suitable site

- Unresectable retroperitoneal tumors involving the kidney

- In infection without response to antibiotic treatment

- When partial vs. radical nephrectomy is discussed (solitary kidney)

\section{Needle size}

Usually 14- to 18-gauge core biopsy needles are used but data regarding complications following multiple biopsies are not available $[99,100]$. The risk of track seeding has not been evaluated.

\section{Contrast-enhanced ultrasound}

The role of CEUS has been described in the EFSUMB guidelines and is useful to delineate necrotic areas [33].

\section{Recommendation 23}

Percutaneous renal biopsy should be performed under ultrasound guidance (LoE 3a, GoR B). Strong consensus (100\%).

\section{Recommendation 24}

Spring-loaded needles for native parenchymal kidney biopsies are superior to manual needles (LoE $2 \mathrm{~b}, \mathrm{GoR} B$ ). Strong consensus $(100 \%)$.

\section{Recommendation 25}

Two adequate samples should be obtained with parenchymal kidney biopsies (LoE 3b, GoR B). Strong consensus (100\%).

\section{Recommendation 26}

$18 \mathrm{G}$ needles should be used as they combine a high diagnostic yield and a relatively low complication rate in native kidneys (LoE 2a, GoR B). Broad agreement (90\%).
Recommendation 27

Post-procedural care is recommended for at least $8-12$ hours after renal biopsies (LoE 3a, GoR B). Strong consensus (96\%).

Recommendation 28

Percutaneous biopsy should be considered in cases of solid focal renal masses when there is a significant probability for a change in patient management (LoE 2a, GoR C). Strong consensus $(100 \%)$.

\section{Recommendation 29}

$18 \mathrm{G}$ needles are recommended for solid focal renal lesions (LoE 4, GoR C). Strong consensus (100\%).

\section{Adrenal Gland \\ $\nabla$}

Imaging modalities

Adrenal masses can be detected by transabdominal grayscale US with high accuracy [101-105]: 99\% and 69\% for the right and left adrenal glands, respectively [101]. Ultrasound, although sensitive, is not capable of accurately differentiating adrenal lesions [106]. Contrast-enhanced ultrasound for the characterization of adrenal masses has been evaluated [107, 108], demonstrating no specific patterns distinguishing benign from malignant lesions [107].

\section{Multidisciplinary decision}

Most adrenal masses not typical for adenoma and not characteristic for a pheochromocytoma on CECT and MRI may require biopsy, especially with a background of known or suspected malignancy $[109,110]$. A biopsy of a possible pheochromocytoma is contentious because of the risk of severe hypertension [111] and clinical and laboratory evaluation is advised prior to biopsy [112-114].

\section{Indications for adrenal biopsy}

- Staging a known malignancy.

- Identifying an unknown primary malignancy.

- Differentiating benign from malignant lesions in equivocal cases [114].

\section{Relative contraindications to adrenal biopsy \\ - Uncorrectable coagulopathy. \\ - Inability to reach the tumor using a safe path. \\ - An unsafe target $[114,115]$.}

\section{INVUS procedure}

The benefits of US guidance include real-time multi-planar imaging, absence of radiation, low cost, portability, and the ability to rapidly confirm complications such as bleeding. The drawbacks of US guidance include inadequate visualization of the target or needle due to operator experience, lesion depth, or intervening bowel gas or bony structures. Use of US identifies the pleural reflection and lung edge to avoid diaphragmatic penetration [114]. 


\section{Materials and technical issues}

Routine pre-procedural blood investigations including full blood count (FBC), metabolic panel and coagulation studies (PT, PTT, INR) are performed.

\section{Description of the intervention}

Right-sided adrenal biopsies can be performed through a trans-hepatic, direct posterior or right-decubitus (target side down) approach. Left-sided adrenal biopsies can be approached with the patient in the left-decubitus position, posteriorly or anteriorly/ transgastric $[116,117]$. Smaller FNA needles $(21$ - 23G) may be preferred when sampling hypervascular lesions, especially when surrounded by bowel or blood vessels, or in the setting of malignancy $[118,119]$. If FNA is chosen, a capillary pass technique is used. Syringe aspiration may traumatize the lesion so that a bloody sample is obtained.

\section{Role of cytology}

The overall sensitivity of FNA in detecting the presence of malignancy is $85 \%[120-122]$.

\section{Complications}

The most frequent complications following adrenal biopsy are hemorrhage and pneumothorax. The overall complication rate is $5.3 \%$. Most are minor, self-limiting complications. The rate of major complications requiring further treatment is $0.4-2 \%[116$, $117,123]$

\section{Recommendation 30}

Adrenal masses incidentally detected at US or indeterminate at $\mathrm{CT}$ should be characterized with MR imaging and/or PET imaging (LoE 2b, GoR B). Strong consensus (97\%)

\section{Recommendation 31}

An ultrasound-guided adrenal biopsy should be considered in lesions that are indeterminate at imaging (LoE 2b, GoR B). Strong consensus (100\%)

\section{Recommendation 32}

Prior to adrenal biopsy, pheochromocytoma should be excluded by biochemical assessment in patients with a clinical suspicion (LoE 5, GoR D). Strong consensus (100\%).

\section{Gastrointestinal tract}

$\nabla$

\section{Indications and contraindications}

Most neoplastic lesions of the gastrointestinal (GI) tract develop as mucosal masses and endoscopic biopsy is the traditional procedure to characterize and obtain a tissue sample. Ultrasound or CT guidance is reserved for specific situations where an appropriate approach by endoscopy or EUS is not feasible [124]. The indications for US-guided biopsy of GI tract lesions are:

- Beyond easy reach of the endoscope (small bowel lesions)

- Submucosal, subserosal and exophytic lesions, especially gastric tumors, e.g. gastrointestinal stromal tumors (GIST) or lymphoma
- Failed biopsy attempts by endoscopic means [124 - 126]

It is usually safe to pass through stomach and small bowel segments with 18-gauge needles [127].

\section{Imaging modalities}

EUS-guided biopsy is the procedure of choice for submucosal, subserosal, or exophytic lesions [128]. CT guidance may be preferred for some lesions, especially those located deep in the pelvis or behind a gas-filled bowel.

\section{Multidisciplinary decision}

The indication for US-guided biopsy of a GI tract lesion should be determined by a multidisciplinary team:

- Availability of advanced endoscopic techniques (i. e., EUS and enteroscopy) [129, 130]

- Suspicion of malignancy and assessment of operability

- Probability that the result of the biopsy will alter management (i.e., starting systemic antibiotic therapy in a tuberculous lesion instead of surgery)

\section{Materials and technical issues}

Sampling may be performed by means of FNA or core biopsy [124-126].

\section{Results}

Sensitivity and accuracy between 80 -99\% have been reported for GI tract biopsies with large needles in retrospective series [124 - 126, 131]. Fine needles perform less well with sensitivities of $45-50 \%$ [126]. To increase the sensitivity, CEUS guidance may be used in larger lesions (especially gastric GIST tumors) to target non-necrotic, viable tissue [132].

\section{Complications}

Complications are rare $(<1 \%)$ for GI tract diagnostic interventions and include hemorrhage and infection related to perforation [131].

\section{Recommendation 33}

GI tumors not characterized by endoscopic biopsy can alternatively be biopsied by percutaneous or endoscopic US guidance (LoE 4, GoR C). Strong consensus (100\%).

\section{Peritoneal cavity and mesentery}

\section{Indications and contraindications}

The peritoneum, including the omentum and mesentery, is a common site for secondary disease extension from adjacent visceral organs and distant metastatic deposits, and is an unusual site of primary neoplastic disease. Non-neoplastic processes (e.g. granulomatous diseases, hematomas, infectious or inflammatory conditions) may also involve the peritoneum, mimicking neoplastic disorders.

\section{Imaging modalities}

Contrast-enhanced computed tomography is the modality of choice for diagnosis, supplemented by MRI and PET/CT techniques [133]. Percutaneous imaging-guided biopsy is safe with a sensitivity of $93 \%$, specificity of $86 \%$, and negative predictive value (NPV) of $50 \%$. In patients with a known primary malignancy, 
the sensitivity of the biopsy procedure is $93 \%$, the specificity is $100 \%$ and the NPV is $38 \%$. In patients without a known primary neoplasm, the sensitivity is $96 \%$, the specificity is $75 \%$ and the NPV is $75 \%$ [134-136].

\section{Multidisciplinary decision}

Peritoneal mass biopsy should be considered at an early stage in the investigation of any patient with no diagnosis. Biopsy is not required if the mass is part of progressive disease and histological diagnosis has previously been obtained. Biopsy is performed if there is uncertainty of recurrence or possible new disease.

Peritoneal masses in patients with a history of cancer are nearly always malignant (86\%) [136]. Biopsy is still indicated; $10 \%$ of patients with a known primary malignant neoplasm will have a second malignant tumor. Biopsy is also indicated in patients without a known primary cancer; benign-appearing peritoneal tissue is predictive of a benign lesion in $75 \%$ of cases [136].

\section{What defines the possibility of performing an INVUS procedure?}

The criteria for performing biopsy are a thick peritoneum or presence of a mesenteric mass on diagnostic imaging. The multiplanar capability of US allows the operator to avoid vessels, the bowel and solid viscera. CT should be reserved for small lesions or disease that is inaccessible to US.

\section{Materials and Technical Issues}

Peritoneal masses are localized with US using graded compression to displace overlying tissue and bowel, employing either a low-frequency or high-frequency transducer. The needle path is assessed with color Doppler US to ensure blood vessels are avoided. Local anesthetic ( $1-2 \%$ lidocaine hydrochloride) can be administered subcutaneously into the abdominal wall. Fine needle aspiration is typically performed using 20-25-gauge needles and provides samples for cytologic examination, whereas CNB is performed using 16-20-gauge needles and provides tissue for histologic assessment [137].

\section{Complications}

In those patients with large-volume ascites, biopsy should not be performed until the ascites is reduced. The anatomical features of the peritoneum will result in a superficial location of the lesions, adhering to the abdominal wall, thus avoiding underlying organs during biopsy. Minor complications related to percutaneous biopsy procedures are seen in $2.7 \%$ patients, unrelated to needle size.

\section{Follow-up}

In patients with a known malignancy, obtaining benign-appearing peritoneal tissue has a low NPV, which means that with a negative biopsy result a repeat biopsy or surgery should be considered to exclude a malignant process [136].

\section{Recommendation 34}

Imaging-guided percutaneous biopsy of the peritoneum is a safe and effective means of providing a tissue diagnosis (LoE 2b, GoR B). Strong consensus (100\%).

\section{Recommendation 35}

Ultrasound can be used for peritoneal mass biopsy (LoE 3b, GoR B). Broad agreement (87\%).
Recommendation 36

In the case of ascites of unknown origin, a biopsy of thickened peritoneum may be considered an alternative to laparoscopic biopsy (LoE 3b, GoR B). Broad agreement (93\%).

\section{Lymph Nodes}

Indications and contraindications

Cross-sectional imaging examinations reveal abdominal (mesenteric/retroperitoneal) lymph nodes with increasing frequency entailing further diagnostic workup as many neoplastic, inflammatory and infectious diseases produce abdominal lymphadenopathy [138].

\section{Imaging modalities}

Chest X-ray and CECT imaging of the neck, chest and abdomen are mandatory to evaluate the stage of the disease. Pathological analysis of the disease process is of paramount importance and is the reference standard for diagnosis [139].

\section{Multidisciplinary decision}

With any primary carcinoma it is important to identify abdominal lymphadenopathy as this affects staging and management. Lymph node biopsy is adequate for the diagnosis of metastatic carcinoma. In the assessment for lymphoma, an entire lymph node is desirable

\section{What defines the possibility of performing an INVUS?}

Ultrasound-guided biopsy of abdominal lymph nodes is considered feasible if the lymph nodes are visible and a safe route is available [140] but CT-guided biopsy is the preferred technique [141-144]. CT-guided CNB is adequate to establish a diagnosis in $82.5 \%$ of patients with lymphoproliferative disorders and should be deployed first in the diagnosis of any lymphoma [142]. Ultrasound allows continuous real-time visualization of the needle tip throughout the procedure, minimizing injury to adjacent critical structures and contamination with blood or extraneous tissue [145].

\section{Materials and technical Issues}

Fine needle aspiration with adjuvant flow cytometry for diagnosing and sub-typing malignant lymphomas has been reported [139] but CNB provides additional diagnostic and prognostic information that may not be easily derived from FNA [146].

With CNB, a diagnostic rate of $83-96 \%$ is reported for lymphoma and should be the procedure of choice for histological sampling in the absence of peripheral lymphadenopathy [147 - 149].

Core needle biopsy is performed most often with large core needles ( $\leq 14$ gauge), while smaller needles ( $\leq 25$ gauge) are used more readily for FNA.

\section{Description of technique}

Grayscale imaging and color Doppler are used to localize the lymph node and to select the shortest route free of vascular structures. Applying pressure with the transducer displaces and minimizes intervening bowel loops and fatty tissue. Usually two needle passes are performed, avoiding any necrotic area of the target lymph node. CEUS can be used [132]. The operator should 
evaluate the specimen visually both before and after placing the sample into a $10 \%$ formalin solution.

\section{Complications}

An abdominal lymph node biopsy is usually well tolerated with a low rate of complications [142]. Local hematoma and post-procedural pain are described in $1.8 \%$ of cases, while bleeding requiring surgery is seen in $1 \%$ [150].

\section{Follow-up}

Patients must be monitored for 4 hours after biopsy procedures to check vital signs and assess for complications.

\section{Recommendation 37}

Percutaneous ultrasound provides accurate and safe guidance for abdominal lymph node biopsy (LoE 3b, GoR B). Strong consensus (100\%).

\section{Recommendation 38}

Percutaneous core needle lymph node biopsy should be used as the method of choice if lymphoma is suspected (LoE 3b, GoR B). Strong consensus (100\%).

\section{Recommendation 39}

In suspicious lymph nodes either core needle biopsy or fine needle biopsy/aspiration may be considered in the presence of known malignancy (LoE 3b, GoR B). Strong consensus (100\%).

\section{Retroperitoneum}

\section{Indications and contraindications}

Retroperitoneal tumors cause symptoms or become palpable only when they have reached a significant size. The most common malignant lesions are sarcomas and lymphomas, while neurogenic tumors, paragangliomas and fibromatosis are the most frequently encountered benign lesions [151].

\section{Other guiding modalities}

CT-guided biopsy of retroperitoneal masses is well-established with good outcome. Fine needle aspiration guided by EUS has a high diagnostic accuracy with lower complications particularly for small lesions $[152,153]$.

\section{Multidisciplinary decision}

The decision to perform a biopsy of a retroperitoneal mass should be made by a multidisciplinary team consisting of a surgeon, oncologist and radiologist. Essentials to support this decision are: imaging features, potential resectability, the probability that the lesion is chemotherapy-sensitive (lymphoma, GIST) or a benign tumor and tumor size [151].

\section{Materials and technical considerations}

With US guidance an anterior approach must be used [154]. Due the risk of injury to large vessels (with subsequent intraperitoneal bleeding) or the bowel, fine needles are usually chosen.

\section{Complications}

In retroperitoneal tumors percutaneous US-guided FNA has a sensitivity of $67-95.8 \%$ depending on the frequency of different diseases in the study population $[145,155,156]$. The accuracy of FNA in diagnosing lymphoma, sarcoma and benign tumors is low. FNA is not indicated when these tumors are suspected [154]. The overall diagnostic rate of US-guided core biopsy was $88.5 \%$. Using CT guidance core biopsy yields a correct diagnosis in $92-96 \%$ of cases [154, 157]. Complications include bleeding (intraperitoneal, retroperitoneal or in abdominal wall), injury of the bowel wall and pain.

\section{Conclusion}

In the management of retroperitoneal tumors, percutaneous biopsy should be performed in certain circumstances. Ultrasound is a valid guidance alternative to CT when biopsy is indicated.

\section{Recommendation 40}

In the case of indeterminate retroperitoneal masses (e.g. sarcoma), the indication for biopsy versus primary resection should be individually assessed (LoE 4, GoR C). Strong consensus $(100 \%)$.

\section{Recommendation 41}

Ultrasound is a valid retroperitoneal biopsy guidance alternative to CT (LoE 4, GoR C). Broad agreement (87\%).

\section{Recommendation $\mathbf{4 2}$}

An ultrasound retroperitoneal core biopsy is more accurate than fine needle aspiration and should be performed whenever possible (LoE 3b, GoR C). Broad agreement (84\%).

\section{Recommendation $\mathbf{4 3}$}

Fine needle aspiration retroperitoneally either percutaneous or by EUS may be an alternative in difficult cases (LoE 4, GoR C). Strong consensus (100\%).

\section{Liver, renal, pancreas and bowel transplant \\ $\nabla$}

\section{Imaging modalities}

Ultrasound is the first-line imaging modality in evaluating all abdominal organ transplants to detect postoperative complications and most interventional procedures will be performed guided by US [158-161]. CT is crucial for the detection of fluid collections $[162,163]$, abscesses and fistulae.

\section{Multidisciplinary decision}

Multidisciplinary teams are involved from the preoperative evaluation and discussion of potential candidates in donor transplant programs to the management of complications throughout hospitalization and follow-up. The multidisciplinary team should include transplant physicians, surgeons, hemato-oncologists, histopathologists, and radiologists with experience in treating transplant patients. 


\section{Indications and contraindications}

\section{Liver transplant}

Indications

- Percutaneous LB is indicated to diagnose diffuse parenchymal abnormality to differentiate between allograft rejection, reperfusion injury, drug-induced toxicity, viral infection or recurrent disease.

- FNA is indicated in the presence of perihepatic collections with suspicion of infection or bile leakage.

- FNB or FNA is indicated with suspicion of neoplastic complications (e.g. hepatocellular carcinoma or post-transplant lymphoproliferative disease (PTLD).

- Protocol LB with normal liver function is accepted to reveal unexpected abnormalities such as progressive fibrosis [164].

\section{Kidney transplant}

Indications

- Renal transplant biopsy is indicated when renal dysfunction is attributable to parenchymal disease, to differentiate between acute rejection and acute tubular necrosis as well as between chronic rejection and immunosuppression toxicity.

- Worsening of renal function or absence of improvement after treatment [165 - 167].

- Prior to altering immunosuppression treatment.

- Protocol transplant biopsies at 3-12 months despite normal renal function to diagnose subclinical allograft dysfunction $[165,168,169]$.

- FNA is indicated in the presence of peri-renal collections with suspicion of infection.

- FNB or FNA are indicated with suspicion of neoplastic complications (e.g. PTLD).

\section{Pancreas transplant}

Indications

- Suspected rejection: persistently or significantly elevated blood glucose level and/or significant reduction in insulin level.

- Follow-up of rejection.

- Clinical protocol in some institutions.

- Suspicion of PTLD.

- FNA to differentiate between the different types of fluid collections (e.g. abscess).

\section{Combined kidney/pancreas transplant}

The majority of pancreas transplants are simultaneous pancreaskidney transplants.

Indications

- Suspected rejection.

- Follow-up of rejection.

Bowel transplant

Surveillance endoscopies for the first few months after intestinal transplantation are performed and endoscopically guided biopsy is required for rejection [170-172].

Indications

- To differentiate between acute rejection, chronic rejection, infections, and a variety of other inflammatory conditions.
Contraindications to all transplant interventions

- Uncorrectable coagulopathy.

- Lesions not detected by US (contraindicated to perform the procedure by US). Fusion imaging with CEUS may allow this to be performed.

\section{Guided biopsy in focal and diffuse lesions}

Biopsies are indicated to diagnose diffuse parenchymal disease and post-transplant focal or diffuse neoplasia including organ malignancy or PTLD.

\section{Description of the intervention}

A variety of needles with different lengths and caliber can be used for INVUS procedures in transplant patients.

Liver transplant biopsy

A biopsy of a liver transplant is performed in the same way as a biopsy of a native liver $[173,174]$. The most common serious complication is post-biopsy bleeding, occurring in $<0.3 \%$ of patients.

Kidney transplant biopsy

The lower renal pole area is preferred. A cortical tangential needle approach to the kidney is preferred, and the needle should remain within the cortex when the biopsy is sampled. The direction of the deviation of the needle caused by the bevel should be towards the periphery of the kidney to reduce the risk of bleeding [175]. Following a renal transplant biopsy, the patient should remain in bed and be monitored for $\geq 4$ hours. Immediately after biopsy, color Doppler US or CEUS can identify any significant bleeding along the puncture tract which may be treated by USguided compression [176]. CEUS may be helpful in diagnosing persistent ongoing bleeding, which may be treated by embolization.

\section{Biopsy of pancreatic transplant}

The pancreatic transplant may be located behind the bowel and firm transducer pressure often allows bowel displacement to visualize the transplant.

The complications are hemorrhage and fistula formation.

\section{Recommendation 44}

Ultrasound should be the first-line imaging modality to detect postoperative complications in organ transplants (LoE 5, GoR D). Strong consensus (100\%).

\section{Recommendation 45}

A biopsy of a liver transplant should be performed using ultrasound (LoE 3b, GoR B). Strong consensus (100\%).

\section{Recommendation 46}

Percutaneous ultrasound-guided biopsy of a renal transplant is a low-risk procedure ( $\mathrm{LoE} 3 \mathrm{~b}, \mathrm{GoR} \mathrm{B})$. Broad agreement $(100 \%)$. 


\section{Recommendation 47}

Color Doppler should be used prior to transplant biopsy to reduce the risk of vascular complications (LoE 5, GoR D). Broad agreement (86\%).

\section{Recommendation 48}

Percutaneous ultrasound-guided pancreatic transplant biopsies are to be performed in expert transplant centers (LoE 5, GoR D). Strong consensus (96\%).

\section{Intervention in the elderly}

When considering an invasive US-guided procedure in an elderly person (defined as $>75$ years), the benefit of making a precise diagnosis should generally have impact on the treatment plan. Based on the current limited literature focusing on the outcome of INVUS in elderly patients, ultrasound-guided tissue sampling and treatment is as safe and accurate as in younger patients [177-180].

\section{Recommendation 49}

The accuracy and complication rate of interventional ultrasound are similar in elderly ( $>75 \mathrm{y}$ ) and younger patients. USguided therapeutic procedures may replace more invasive and radical treatment methods, with an adequate outcome and better patient tolerance (LoE 4, GoR C). Strong consensus (100\%).

\section{Affiliations}

Department of Radiology, King's College Hospital, London, UK

2 Department of Radiology and Nuclear Medicine, Oslo University Hospital, Rikshospitalet, Norway

3 Department of Radiological Sciences, Oncology and Pathology, Policlinico Umberto I, University Sapienza, Rome, Italy

${ }^{4}$ Department of Adult Radiology, Paris-Descartes University and Necker University Hospital, Paris, and Institut Langevin - Inserm U979, Paris, France

5 Department of Internal Medicine 2, Caritas Krankenhaus, Bad Mergentheim, Germany

6 Sino-German Research Center of Ultrasound in Medicine, The First Affiliated Hospital of Zhengzhou University, Zhengzhou, China

7 Department of Radiology, GB Rossi University Hospital, University of Verona, Italy

8 Clinic of Gastroenterology, Departement Visceral Medicine, Inselspital, University Hospital of Bern, Switzerland

9 Department of Radiology, Derriford Hospital, Plymouth, UK

10 National Centre for Ultrasound in Gastroenterology, Haukeland University Hospital, Bergen and Department of Clinical Medicine, University of Bergen, Norway

11 Radiology, Esslinger Hauptstraße 89, 1220 Vienna, Austria

12 Department of Medicine and National Centre for Ultrasound in Gastroenterology, Haukeland University Hospital, Bergen, Norway

13 Department of Internal Medicine, Krankenhaus Märkisch Oderland Strausberg/Wriezen, Germany

14 Department of Radiology, Akdeniz University Medical Faculty, Antalya, Turkey

15 Department of Gastric Surgery, Ultrasound Section, Herlev Hospital, University of Copenhagen, Denmark

16 Department of Nephrology, Hypertension and Clinical Pharmacology, Division of Hypertension, University Hospital Berne, Switzerland

17 Radiology Department, Hospital Clinic, Barcelona, Spain

18 Department of Gastroenterology, Brandenburg University of Medicine Theodor Fontane, Neuruppin, Germany

19 Diagnostic Radiology Institute, Paula Stradins Clinical University Hospital, Riga, Latvia

20 Department of Gastroenterology, Research Center of Gastroenterology and Hepatology, University of Medicine and Pharmacy, Craiova, Romania
21 Department of Endoscopy, Gastrointestinal Unit, Copenhagen University Hospital Herlev, Denmark

22 Diagnostic and Interventional Ultrasound Unit, Department of Organ Failure and Transplantation S. Orsola-Malpighi Hospital Bologna, Italy

23 Department of Gastroenterology, Institute for Gastroenterology and Hepatology, University of Medicine and Pharmacy, "Iuliu Hatieganu” Cluj-Napoca and Institute for Gastroenterology and Hepatology "O. Fodor" Cluj-Napoca, Romania

24 Department of Gastroenterology and Hepatology, University of Medicine and Pharmacy Victor Babes, Timisoara, Romania

\section{Acknowledgement}

We would like to acknowledge the advice from Lynne Rudd, EFSUMB general secretary.

\section{References}

1 Lorentzen T, Nolsoe CP, Ewertsen $C$ et al. EFSUMB Guidelines on Interventional Ultrasound, Part I: General Aspects. Ultraschall in Med 2015; 36: $464-472$

2 Dietrich CF, Lorentzen T, Appelbaum L et al. EFSUMB Guidelines on Interventional Ultrasound, Part III: Abdominal Treatment Procedures. Ultraschall in Med 2015, in press

3 Dietrich CF, Lorentzen T, Sidhu PS et al. An Introduction to the EFSUMB Guidelines on Interventional Ultrasound (INVUS). Ultraschall in Med 2015; 36: 460 - 463

4 Hergesell 0 , Felten $H$, Andrassy $K$ et al. Safety of ultrasound-guided percutaneous renal biopsy-retrospective analysis of 1090 consecutive cases. Nephrol Dial Transplant 1998; 13: 975 - 977

5 Maya ID, Maddela P, Barker J et al. Percutaneous renal biopsy: comparison of blind and real-time ultrasound-guided technique. Semin Dial 2007; 20: 355 - 358

6 Lindor KD, Bru C, Jorgensen RA et al. The role of ultrasonography and automatic-needle biopsy in outpatient percutaneous liver biopsy. Hepatology 1996; 23: 1079-1083

7 Patel IJ, Davidson JC, Nikolic B et al. Consensus guidelines for periprocedural management of coagulation status and hemostasis risk in percutaneous image-guided interventions. J Vasc Interv Radiol 2012; 23 . $727-736$

8 Sue M, Caldwell SH, Dickson RC et al. Variation between centers in technique and guidelines for liver biopsy. Liver 1996; 16: 267-270

9 Knauer CM. Percutaneous biopsy of the liver as a procedure for outpatients. Gastroenterology 1978; 74: $101-102$

10 Grossjohann HS, Bachmann Nielsen M. Ultrasound contrast agents may help in avoiding necrotic areas at biopsy. Ultraschall in Med 2006; 27 : $2-3$

11 Sparchez Z, Radu P, Zaharia T et al. Usefulness of contrast enhanced ultrasound guidance in percutaneous biopsies of liver tumors. J Gastrointestin Liver Dis 2011; 20: 191 - 196

12 Krucker J, Xu S, Venkatesan A et al. Clinical utility of real-time fusion guidance for biopsy and ablation. J Vasc Interv Radiol 2011; 22: 515 524

13 Sainani NI, Arellano RS, Shyn PB et al. The challenging image-guided abdominal mass biopsy: established and emerging techniques 'if you can see it, you can biopsy it'. Abdom Imaging 2013; 38: 672 - 696

14 Strobel D, Bernatik TJ, Blank W et al. Incidence of bleeding in 8172 percutaneous ultrasound-guided intraabdominal diagnostic and therapeutic interventions - results of the prospective multicenter DEGUM interventional ultrasound study (PIUS study). Ultraschall in Med 2015; 36: $122-131$

15 Wilson ML. General principles of specimen collection and transport Clin Infect Dis 1996; 22: 766-777

16 Adam A, Dixon AK, Gillard JH et al. Grainger \& Allison's Diagnostic Radiology; 2014

17 Rockey DC, Caldwell SH, Goodman ZD et al. Liver biopsy. Hepatology 2009; 49: 1017-1044

18 Cholongitas E, Senzolo M, Standish $R$ et al. A systematic review of the quality of liver biopsy specimens. Am J Clin Pathol 2006; 125: $710-721$ 
19 Pasha T, Gabriel S, Therneau T et al. Cost-effectiveness of ultrasoundguided liver biopsy. Hepatology 1998; 27: 1220-1226

20 Younossi ZM, Teran JC, Ganiats TG et al. Ultrasound-guided liver biopsy for parenchymal liver disease: an economic analysis. Dig Dis Sci 1998; 43: $46-50$

21 Riley TR 3rd. How often does ultrasound marking change the liver biopsy site? Am J Gastroenterol 1999; 94: 3320 - 3322

22 Sporea I, Gherhardt D, Popescu A et al. Does the size of the needle influence the number of portal tracts obtained through percutaneous liver biopsy? Ann Hepatol 2012; 11: 691 -695

23 de Man RA, van Buuren HR, Hop WC. A randomised study on the efficacy and safety of an automated Tru-Cut needle for percutaneous liver biopsy. Neth J Med 2004; 62: 441 - 445

24 Jensen DM. Individualizing HCV Treatment with Peginterferon and Ribavirin: What needs to be Done? Therap Adv Gastroenterol 2009; 2: $5-10$

25 Bravo AA, Sheth SG, Chopra S. Liver biopsy. N Engl J Med 2001; 344: 495- 500

26 Ghent $C N$. Percutaneous liver biopsy: reflections and refinements. Can J Gastroenterol 2006; 20: 75-79

27 Giorgio A, Tarantino L, de Stefano G et al. Complications after interventional sonography of focal liver lesions: a 22-year single-center experience. J Ultrasound Med 2003; 22: 193-205

28 Weiss $H$, Duntsch $U$, Weiss A. Risks of fine needle puncture-results of a survey in West Germany(German Society of Ultrasound in Medicine survey). Ultraschall in Med 1988; 9: 121 -127

29 Robertson EG, Baxter G. Tumour seeding following percutaneous needle biopsy: the real story! Clin Radiol 2011; 66: 1007-1014

30 Ein SH, Shandling B, Simpson JS et al. The morbidity and mortality of splenectomy in childhood. Ann Surg 1977; 185: 307-310

31 Aksnes J, Abdelnoor M, Mathisen 0 . Risk factors associated with mortality and morbidity after elective splenectomy. Eur J Surg 1995; 161 : $253-258$

32 Catalano O, Lobianco R, Sandomenico $F$ et al. Real-time contrast-enhanced ultrasound of the spleen: examination technique and preliminary clinical experience. Radiol Med 2003; 106: 338-356

33 Piscaglia F, Nolsoe C, Dietrich CF et al. The EFSUMB Guidelines and Recommendations on the Clinical Practice of Contrast Enhanced Ultrasound (CEUS): update 2011 on non-hepatic applications. Ultraschall in Med 2012; 33: 33-59

34 McInnes MD, Kielar AZ, Macdonald DB. Percutaneous image-guided biopsy of the spleen: systematic review and meta-analysis of the complication rate and diagnostic accuracy. Radiology 2011; 260: 699-708

35 Singh AK, Shankar S, Gervais DA et al. Image-guided percutaneous splenic interventions. Radiographics 2012; 32: 523-534

36 Keogan MT, Freed KS, Paulson EK et al. Imaging-guided percutaneous biopsy of focal splenic lesions: update on safety and effectiveness. Am J Roentgenol 1999; 172: $933-937$

37 O'Malley ME, Wood BJ, Boland GW et al. Percutaneous imaging-guided biopsy of the spleen. Am J Roentgenol 1999; 172: 661-665

38 Lopez JI, Del Cura JL, De Larrinoa AF et al. Role of ultrasound-guided core biopsy in the evaluation of spleen pathology. APMIS 2006; 114: $492-499$

39 Zeppa P, Vetrani A, Luciano L et al. Fine needle aspiration biopsy of the spleen. A useful procedure in the diagnosis of splenomegaly. Acta Cytol 1994; 38: 299-309

40 Lishner $M$, Lang $R$, Hamlet $Y$ et al. Fine needle aspiration biopsy in patients with diffusely enlarged spleens. Acta Cytol 1996; 40: 196-198

41 Lal A, Ariga R, Gattuso P et al. Splenic fine needle aspiration and core biopsy. A review of 49 cases. Acta Cytol 2003; 47: 951 - 959

42 Lucey BC, Boland GW, Maher MM et al. Percutaneous nonvascular splenic intervention: a 10-year review. Am J Roentgenol 2002; 179: 1591 1596

43 Kang $M$, Kalra N, Gulati $M$ et al. Image guided percutaneous splenic interventions. Eur J Radiol 2007; 64: 140-146

44 Civardi G, Vallisa D, Berte R et al. Ultrasound-guided fine needle biopsy of the spleen: high clinical efficacy and low risk in a multicenter Italian study. Am J Hematol 2001; 67: 93-99

45 Lieberman S, Libson E, Maly B et al. Imaging-guided percutaneous splenic biopsy using a 20- or 22-gauge cutting-edge core biopsy needle for the diagnosis of malignant lymphoma. Am J Roentgenol 2003; 181: $1025-1027$

46 Lindgren PG, Hagberg H, Eriksson B et al. Excision biopsy of the spleen by ultrasonic guidance. Br J Radiol 1985; 58: 853-857
47 Liang $P$, Gao Y, Wang $Y$ et al. US-guided percutaneous needle biopsy of the spleen using 18 -gauge versus 21 -gauge needles. J Clin Ultrasound 2007; 35: 477-482

48 Hartwig W, Schneider L, Diener MK et al. Preoperative tissue diagnosis for tumours of the pancreas. Br J Surg 2009; 96: 5-20

49 Cahn M, Chang K, Nguyen P et al. Impact of endoscopic ultrasound with fine-needle aspiration on the surgical management of pancreatic cancer. Am J Surg 1996; 172: 470-472

$50 \mathrm{Kahl} \mathrm{S,} \mathrm{Malfertheiner} \mathrm{P.} \mathrm{Role} \mathrm{of} \mathrm{endoscopic} \mathrm{ultrasound} \mathrm{in} \mathrm{the} \mathrm{diagnosis}$ of patients with solid pancreatic masses. Dig Dis 2004; 22: 26-31

51 Nakamura R, Machado R, Amikura K et al. Role of fine needle aspiration cytology and endoscopic biopsy in the preoperative assessment of pancreatic and peripancreatic malignancies. Int J Pancreatol 1994; 16: $17-21$

52 Tillou A, Schwartz MR, Jordan PH et al. Percutaneous needle biopsy of the pancreas: when should it be performed? World J Surg 1996; 20: 283 - 286; discussion 287

53 Tempero MA, Arnoletti JP, Behrman S et al. Pancreatic adenocarcinoma. J Natl Compr Canc Netw 2010; 8: 972 - 1017

54 Buscarini E, Pezzilli R, Cannizzaro R. Italian Association of Hospital G, Endoscopists, Italian Association for the Study of the P. et al. Italian consensus guidelines for the diagnostic work-up and follow-up of cystic pancreatic neoplasms. Dig Liver Dis 2014; 46: 479-493

55 Tanaka M, Fernandez-del Castillo C, Adsay V et al. International consensus guidelines 2012 for the management of IPMN and MCN of the pancreas. Pancreatology 2012; 12: 183-197

56 van der Waaij LA, van Dullemen HM, Porte RJ. Cyst fluid analysis in the differential diagnosis of pancreatic cystic lesions: a pooled analysis. Gastrointest Endosc 2005; 62: 383-389

57 D'Onofrio M, Gallotti A, Pozzi Mucelli R. Imaging techniques in pancreatic tumors. Expert Rev Med Devices 2010; 7: 257-273

58 Park MK, Jo J, Kwon $\mathrm{H}$ et al. Usefulness of acoustic radiation force impulse elastography in the differential diagnosis of benign and malignant solid pancreatic lesions. Ultrasonography 2014; 33: 26-33

59 Low G, Panu A, Millo $N$ et al. Multimodality imaging of neoplastic and nonneoplastic solid lesions of the pancreas. Radiographics 2011; 31: $993-1015$

60 D'Onofrio M, Crosara S, Signorini $M$ et al. Comparison between CT and CEUS in the diagnosis of pancreatic adenocarcinoma. Ultraschall in Med 2013; 34: 377-381

61 Yang RY, Ng D, Jaskolka JD et al. Evaluation of percutaneous ultrasoundguided biopsies of solid mass lesions of the pancreas: a center's 10year experience. Clin Imaging 2015; 39: $62-65$

62 Zamboni GA, D'Onofrio $M$, Idili A et al. Ultrasound-guided percutaneous fine-needle aspiration of 545 focal pancreatic lesions. Am J Roentgenol 2009; 193: 1691 - 1695

63 Garre Sanchez MC, Rendon Unceta P, Lopez Cano A et al. Ultrasoundguided biopsy of the pancreas: a multicenter study. Rev Esp Enferm Dig 2007; 99: 520-524

64 Emerson RE, Randolph ML, Cramer HM. Endoscopic ultrasound-guided fine-needle aspiration cytology diagnosis of intraductal papillary mucinous neoplasm of the pancreas is highly predictive of pancreatic neoplasia. Diagn Cytopathol 2006; 34: 457-462

65 Pais SA, Attasaranya S, Leblanc JK et al. Role of endoscopic ultrasound in the diagnosis of intraductal papillary mucinous neoplasms: correlation with surgical histopathology. Clin Gastroenterol Hepatol 2007; 5: 489-495

66 Attasaranya S, Pais S, LeBlanc J et al. Endoscopic ultrasound-guided fine needle aspiration and cyst fluid analysis for pancreatic cysts. JOP 2007; 8: 553-563

67 Stelow EB, Shami VM, Abbott TE et al. The use of fine needle aspiration cytology for the distinction of pancreatic mucinous neoplasia. Am J Clin Pathol 2008; 129: 67- 74

68 Belsley NA, Pitman MB, Lauwers GY et al. Serous cystadenoma of the pancreas: limitations and pitfalls of endoscopic ultrasound-guided fine-needle aspiration biopsy. Cancer 2008; 114: 102-110

69 Otto R. Interventional ultrasound. Eur Radiol 2002; 12: 283-287

70 Bret PM, Nicolet V, Labadie M. Percutaneous fine-needle aspiration biopsy of the pancreas. Diagn Cytopathol 1986; 2: 221-227

71 Hall-Craggs MA, Lees WR. Fine-needle aspiration biopsy: pancreatic and biliary tumors. Am J Roentgenol 1986; 147: 399-403

72 Brandt KR, Charboneau JW, Stephens DH et al. CT- and US-guided biopsy of the pancreas. Radiology 1993; 187: 99-104 
73 Di Stasi M, Lencioni $R$, Solmi $L$ et al. Ultrasound-guided fine needle biopsy of pancreatic masses: results of a multicenter study. Am J Gastroenterol 1998; 93: 1329-1333

74 Mallery JS, Centeno BA, Hahn PF et al. Pancreatic tissue sampling guided by EUS, CT/US, and surgery: a comparison of sensitivity and specificity. Gastrointest Endosc 2002; 56: 218-224

75 Bosman FT. World Health Organization, International Agency for Research on Cancer.. WHO Classification of Tumours of the Digestive System. 4th ed. Lyon: International Agency for Research on Cancer; 2010

76 Sperti C, Pasquali C, Di Prima F et al. Percutaneous CT-guided fine needle aspiration cytology in the differential diagnosis of pancreatic lesions. Ital J Gastroenterol 1994; 26: 126-131

77 Zech CJ, Helmberger T, Wichmann MW et al. Large core biopsy of the pancreas under CT fluoroscopy control: results and complications. J Comput Assist Tomogr 2002; 26: 743 - 749

78 Smith $\mathrm{EH}$. Complications of percutaneous abdominal fine-needle biopsy. Review. Radiology 1991; 178: 253 - 258

79 Dietrich CF. Endoscopic ultrasound; 2013

80 Rodriguez JR, Razo AO, Targarona J et al. Debridement and closed packing for sterile or infected necrotizing pancreatitis: insights into indications and outcomes in 167 patients. Ann Surg 2008; 247: 294-299

81 Rau B, Pralle U, Mayer JM et al. Role of ultrasonographically guided fine-needle aspiration cytology in the diagnosis of infected pancreatic necrosis. Br J Surg 1998; 85: 179-184

82 Nicholson ML, Wheatley TJ, Doughman TM et al. A prospective randomized trial of three different sizes of core-cutting needle for renal transplant biopsy. Kidney Int 2000; 58: 390 - 395

83 Dietrich CF, Nuernberg D. Interventional Ultrasound: A Practical Guide and Atlas. Stuttgart, New York, Delhi, Rio: Thieme publisher; 2014

84 Doyle AJ, Gregory MC, Terreros DA. Percutaneous native renal biopsy: comparison of a 1.2-mm spring-driven system with a traditional 2-mm hand-driven system. Am J Kidney Dis 1994; 23: 498 - 503

85 Ham WS, Lee JH, Kim WT et al. Comparison of multiple session 99\% ethanol and single session OK-432 sclerotherapy for the treatment of simple renal cysts. J Urol 2008; 180: 2552 - 2556

86 Chunduri S, Whittier WL, Korbet SM. Adequacy and Complication Rates with 14- vs. 16-gauge Automated Needles in Percutaneous Renal Biopsy of Native Kidneys. Semin Dial 2014

87 Irshad A, Ackerman SJ, Campbell AS et al. An overview of renal transplantation: current practice and use of ultrasound. Semin Ultrasound CT MR 2009; 30: 298-314

88 Burstein DM, Korbet SM, Schwartz MM. The use of the automatic core biopsy system in percutaneous renal biopsies: a comparative study. Am J Kidney Dis 1993; 22: 545 - 552

89 Rohl L, Rasmussen OS. Ultrasound-guided percutaneous suprapubic cystostomy. European Journal of Ultrasound 1997; 6: 57-61

90 Marwah DS, Korbet SM. Timing of complications in percutaneous renal biopsy: what is the optimal period of observation? Am J Kidney Dis 1996; $28: 47-52$

91 Waldo B, Korbet SM, Freimanis MG et al. The value of post-biopsy ultrasound in predicting complications after percutaneous renal biopsy of native kidneys. Nephrol Dial Transplant 2009; 24: 2433-2439

92 Whittier WL, Korbet SM. Timing of complications in percutaneous renal biopsy. J Am Soc Nephrol 2004; 15: 142 - 147

93 Prasad N, Kumar S, Manjunath $R$ et al. Real-time ultrasound-guided percutaneous renal biopsy with needle guide by nephrologists decreases post-biopsy complications. Clin Kidney J 2015; 8: 151 - 156

94 Peters B, Andersson Y, Stegmayr B et al. A study of clinical complications and risk factors in 1001 native and transplant kidney biopsies in Sweden. Acta Radiol 2014; 55: 890-896

95 Manno C, Strippoli GF, Arnesano L et al. Predictors of bleeding complications in percutaneous ultrasound-guided renal biopsy. Kidney Int 2004; 66: $1570-1577$

96 Remzi M, Marberger M. Renal tumor biopsies for evaluation of small renal tumors: why, in whom, and how? Eur Urol 2009; 55: 359 - 367

97 Shannon BA, Cohen RJ, de Bruto $H$ et al. The value of preoperative needle core biopsy for diagnosing benign lesions among small, incidentally detected renal masses. J Urol 2008; 180: 1257-1261

98 Wang $R$, WolfJS Jr, Wood DPJr et al. Accuracy of percutaneous core biopsy in management of small renal masses. Urology 2009; 73: 586-590

99 Korivi BR, Elsayes KM. Cross-sectional imaging work-up of adrenal masses. World J Radiol 2013; 5: 88-97

100 Mai J, Yong J, Dixson H et al. Is bigger better? A retrospective analysis of native renal biopsies with 16 Gauge versus 18 Gauge automatic needles. Nephrology (Carlton) 2013; 18: 525-530
101 Dietrich CF, Wehrmann T, Hoffmann C et al. Detection of the adrenal glands by endoscopic or transabdominal ultrasound. Endoscopy 1997; 29: $859-864$

102 Liao JT, Huang TH, Wu BY. Ultrasonographic evaluation of adrenal masses. Hunan Yi Ke Da Xue Xue Bao 2001; 26: 453-454

103 Lumachi F, Borsato S, Brandes AA et al. Fine-needle aspiration cytology of adrenal masses in noncancer patients: clinicoradiologic and histologic correlations in functioning and nonfunctioning tumors. Cancer 2001; 93: $323-329$

104 Suzuki Y, Sasagawa I, Suzuki H et al. The role of ultrasonography in the detection of adrenal masses: comparison with computed tomography and magnetic resonance imaging. Int Urol Nephrol 2001; 32: $303-306$

105 Trojan J, Schwarz W, Sarrazin C et al. Role of ultrasonography in the detection of small adrenal masses. Ultraschall in Med 2002; 23: $96-100$

106 Yeh HC. US and CT evaluation of diffusely enlarged adrenal gland. Crit Rev Diagn Imaging 1992; 33: 437 - 460

107 Dietrich CF, Ignee A, Barreiros AP et al. Contrast-enhanced ultrasound for imaging of adrenal masses. Ultraschall in Med 2010; 31: $163-168$

108 Friedrich-Rust M, Schneider G, Bohle RM et al. Contrast-enhanced sonography of adrenal masses: differentiation of adenomas and nonadenomatous lesions. Am J Roentgenol 2008; 191: 1852 - 1860

109 Arnold DT, Reed JB, Burt K. Evaluation and management of the incidental adrenal mass. Proc (Bayl Univ Med Cent) 2003; 16: 7-12

110 Ilias I, Sahdev A, Reznek RH et al. The optimal imaging of adrenal tumours: a comparison of different methods. Endocr Relat Cancer 2007; 14: $587-599$

111 Vanderveen KA, Thompson SM, Callstrom MR et al. Biopsy of pheochromocytomas and paragangliomas: potential for disaster. Surgery 2009; 146: $1158-1166$

112 Young WF Jr. Clinical practice. The incidentally discovered adrenal mass. N Engl J Med 2007; 356: 601 -610

113 Khati NJ, Gorodenker J, Hill MC. Ultrasound-guided biopsies of the abdomen. Ultrasound Q 2011; 27: 255-268

114 Sharma KV, Venkatesan AM, Swerdlow D et al. Image-guided adrenal and renal biopsy. Tech Vasc Interv Radiol 2010; 13: 100 - 109

115 Desai S, Nemcek AA. Percutaneous Biopsy. In: Desai S, Nemcek AA eds Image-Guided Interventions. Volume 2.1. Philadelphia: PA: Saunders; 2008: $1339-1344$

116 Silverman SG, Mueller PR, Pinkney LP et al. Predictive value of imageguided adrenal biopsy: analysis of results of 101 biopsies. Radiology $1993 \cdot 187: 715-718$

117 Welch TJ, Sheedy PF 2nd, Stephens DH et al. Percutaneous adrenal biopsy: review of a 10-year experience. Radiology 1994; 193: 341 344

118 Gupta S, Madoff DC. Image-guided percutaneous needle biopsy in cancer diagnosis and staging. Tech Vasc Interv Radiol 2007; 10: 88 101

119 Winter TC, Lee FT Jr, Hinshaw JL. Ultrasound-guided biopsies in the abdomen and pelvis. Ultrasound Q 2008; 24: 45-68

$120 \mathrm{Katz}$ RL. Kidney, adrenal, reteroperitoneum. In: Bibbo M ed. Comprehensive cytopathology. Philadelphia: WB Saunders; 1991: 771-806

121 Katz RL, Patel S, Mackay B et al. Fine needle aspiration cytology of the adrenal gland. Acta Cytol 1984; 28: 269-282

122 Rana C, Krishnani N, Kumari N. Spectrum of adrenal lesions on fine needle aspiration cytology. Indian J Pathol Microbiol 2012; 55: 461 466

123 Mody MK, Kazerooni EA, Korobkin M. Percutaneous CT-guided biopsy of adrenal masses: immediate and delayed complications. J Comput Assist Tomogr 1995; 19: 434-439

124 Perez-Johnston $R$, Hahn PF, Shenoy-Bhangle AS et al. Percutaneous biopsy of focal lesions of the gastrointestinal tract. Abdom Imaging 2013; 38: $1197-1202$

125 Farmer KD, Harries SR, Fox BM et al. Core biopsy of the bowel wall: efficacy and safety in the clinical setting. Am J Roentgenol 2000; 175: 1627 - 1630

126 Marco-Domenech SF, Gil-Sanchez S, Fernandez-Garcia Pet al. Sonographically guided percutaneous biopsy of gastrointestinal tract lesions. Am J Roentgenol 2001; 176: 147 - 151

127 Tudor GR, Rodgers PM, West KP. Bowel lesions: percutaneous US-guided 18-gauge needle biopsy-preliminary experience. Radiology 1999; 212: $594-597$

128 Tombesi $P$, Postorivo S, Catellani $M$ et al. Percutaneous ultrasonography-guided core needle biopsy of gastrointestinal lesions: what's its 
actual role in clinical practice? A retrospective study for safety and effectiveness. Ultraschall in Med 2011; 32: S62 - S67

129 Chen VK, Eloubeidi MA. Endoscopic ultrasound-guided fine-needle aspiration of intramural and extraintestinal mass lesions: diagnostic accuracy, complication assessment, and impact on management. Endoscopy 2005; 37: $984-989$

130 Pasha SF, Leighton JA. Endoscopic techniques for small bowel imaging. Radiol Clin North Am 2013; 51: 177-187

131 de Sio I, Funaro A, Vitale LM et al. Ultrasound-guided percutaneous biopsy for diagnosis of gastrointestinal lesions. Dig Liver Dis 2013; 45: $816-819$

132 Sparchez Z, Radu P, Zaharia T et al. Contrast enhanced ultrasound guidance: a new tool to improve accuracy in percutaneous biopsies. Med Ultrason 2010; 12: 133-138

133 Patel CM, Sahdev A, Reznek RH. CT, MRI and PET imaging in peritoneal malignancy. Cancer Imaging 2011; 11: 123-139

134 Spencer JA, Swift SE, Wilkinson $N$ et al. Peritoneal carcinomatosis: image-guided peritoneal core biopsy for tumor type and patient care. Radiology 2001; 221: $173-177$

135 Layfield LJ, Gopez EV. Percutaneous image-guided fine-needle aspiration of peritoneal lesions. Diagn Cytopathol 2003; 28: 6-12

136 Souza FF, Mortele KJ, Cibas ES et al. Predictive value of percutaneous imaging-guided biopsy of peritoneal and omental masses: results in 111 patients. Am J Roentgenol 2009; 192: 131 - 136

137 Stewart CJ, Coldewey J, Stewart IS. Comparison of fine needle aspiration cytology and needle core biopsy in the diagnosis of radiologically detected abdominal lesions. J Clin Pathol 2002; 55: 93-97

138 Lucey BC, Stuhlfaut JW, Soto JA. Mesenteric lymph nodes seen at imaging: causes and significance. Radiographics 2005; 25: 351-365

139 Nahar Saikia U, Khirdwadkar N, Saikia B et al. Image-guided fine-needle aspiration cytology of deep-seated enlarged lymph nodes. Acta Radiol 2002; 43: 230-234

140 Memel DS, Dodd GD 3rd, Esola CC. Efficacy of sonography as a guidance technique for biopsy of abdominal, pelvic, and retroperitoneal lymph nodes. Am J Roentgenol 1996; 167: 957-962

141 Hesselmann V, Zahringer M, Krug B et al. Computed-tomographyguided percutaneous core needle biopsies of suspected malignant lymphomas: impact of biopsy, lesion, and patient parameters on diagnostic yield. Acta Radiol 2004; 45: $641-645$

142 Agid R, Sklair-Levy M, Bloom AI et al. CT-guided biopsy with cuttingedge needle for the diagnosis of malignant lymphoma: experience of 267 biopsies. Clin Radiol 2003; 58: $143-147$

143 Li L, Wu QL, Liu LZ et al. Value of CT-guided core-needle biopsy in diagnosis and classification of malignant lymphomas using automated biopsy gun. World J Gastroenterol 2005; 11: $4843-4847$

144 Balestreri L, Morassut S, Bernardi D et al. Efficacy of CT-guided percutaneous needle biopsy in the diagnosis of malignant lymphoma at first presentation. Clin Imaging 2005; 29: 123-127

145 Gupta S, Rajak CL, Sood BP et al. Sonographically guided fine needle aspiration biopsy of abdominal lymph nodes: experience in $102 \mathrm{pa}-$ tients. J Ultrasound Med 1999; 18: 135 - 139

146 Ravinsky E, Morales C. Diagnosis of lymphoma by image-guided needle biopsies: fine needle aspiration biopsy, core biopsy or both? Acta Cytol 2005; 49: $51-57$

147 de Kerviler E, Guermazi A, Zagdanski AM et al. Image-guided core-needle biopsy in patients with suspected or recurrent lymphomas. Cancer 2000; 89: 647-652

148 Pappa VI, Hussain HK, Reznek RH et al. Role of image-guided core-needle biopsy in the management of patients with lymphoma. J Clin Oncol 1996; 14: $2427-2430$

149 Zinzani PL, Colecchia A, Festi D et al. Ultrasound-guided core-needle biopsy is effective in the initial diagnosis of lymphoma patients. Haematologica 1998; 83: 989-992

150 Zikan M, Fischerova D, Pinkavova I et al. Ultrasound-guided tru-cut biopsy of abdominal and pelvic tumors in gynecology. Ultrasound Obstet Gynecol 2010; 36: 767-772

151 Strauss DC, Hayes AJ, Thomas JM. Retroperitoneal tumours: review of management. Ann R Coll Surg Engl 2011; 93: 275 - 280

152 Anand D, Barroeta JE, Gupta PK et al. Endoscopic ultrasound guided fine needle aspiration of non-pancreatic lesions: an institutional experience. J Clin Pathol 2007; 60: 1254-1262

153 Wang YH, Ding XW, Chen DJ. Clinical analysis for the application of endoscopic ultrasonography in the diagnosis of patients with a retroperitoneal space-occupying lesion. Saudi Med J 2012; 33: 44-49
154 Stattaus J, Kalkmann J, Kuehl H et al. Diagnostic yield of computed tomography-guided coaxial core biopsy of undetermined masses in the free retroperitoneal space: single-center experience. Cardiovasc Intervent Radiol 2008; 31: 919-925

155 Gangopadhyay M, Bhattacharyya NK, Ray S et al. Guided fine needle aspiration cytology of retroperitoneal masses - Our experience. J Cytol 2011; $28: 20-24$

156 Chakrabarti I, Bhowmik S, Sinha MG et al. Ultrasound-guided aspiration cytology of retroperitoneal masses with histopathological corroboration: A study of 71 cases. J Cytol 2014; 31: 15-19

157 Tomozawa Y, Inaba Y, Yamaura $H$ et al. Clinical value of CT-guided needle biopsy for retroperitoneal lesions. Korean J Radiol 2011; 12 : $351-357$

158 Elsayes KM, Menias CO, Willatt J et al. Imaging of renal transplant: utility and spectrum of diagnostic findings. Curr Probl Diagn Radiol 2011; 40: 127-139

159 Yates A, Parry C, Stephens $M$ et al. Imaging pancreas transplants. Br J Radiol 2013; 86: 20130428

160 Caiado AH, Blasbalg R, Marcelino AS et al. Complications of liver transplantation: multimodality imaging approach. Radiographics 2007; 27: $1401-1417$

161 Singh AK, Nachiappan AC, Verma HA et al. Postoperative imaging in liver transplantation: what radiologists should know. Radiographics 2010; 30: 339-351

162 Sebastia C, Quiroga S, Boye R et al. Helical CT in renal transplantation: normal findings and early and late complications. Radiographics 2001; $21: 1103-1117$

163 Quiroga S, Sebastia MC, Margarit C et al. Complications of orthotopic liver transplantation: spectrum of findings with helical CT. Radiographics 2001; 21: 1085-1102

164 Berenguer M, Rayon JM, Prieto $M$ et al. Are posttransplantation protocol liver biopsies useful in the long term? Liver Transpl 2001; 7: 790 796

165 Wilkinson A. Protocol transplant biopsies: are they really needed? Clin J Am Soc Nephrol 2006; 1: 130-137

166 Seron $D$, Moreso F. Protocol biopsies in renal transplantation: prognostic value of structural monitoring. Kidney Int 2007; 72: 690-697

167 Nankivell BJ, Fenton-Lee CA, Kuypers DR et al. Effect of histological damage on long-term kidney transplant outcome. Transplantation 2001; 71: 515-523

168 Garcia-Rubio JH, Garcia JR, Hernandez PC et al. Correlation between dual kidney biopsy in expanded-criteria donors and transplant survival. Transplant Proc 2013; 45: 3606-3608

169 Schwarz A, Mengel M, Gwinner W et al. Protocol biopsy program after renal transplantation: structure and first results. Transplant Proc 2002; 34: $2238-2239$

170 Sandrasegaran $K$, Lall C, Ramaswamy $R$ et al. Intestinal and multivisceral transplantation. Abdom Imaging 2011; 36: 382 - 389

171 Ruiz P. Updates on acute and chronic rejection in small bowel and multivisceral allografts. Curr Opin Organ Transplant 2014; 19: 293 302

172 Godfrey EM, Upponi SS, See TC et al. A radiologist's guide to small bowel and multivisceral transplantation. Clin Radiol 2013; 68: 983-991

173 Al Knawy B, Shiffman M. Percutaneous liver biopsy in clinical practice. Liver Int 2007; 27: 1166-1173

174 Strassburg CP, Manns MP. Approaches to liver biopsy techniques-revisited. Semin Liver Dis 2006; 26: 318-327

175 Patel MD, Phillips CJ, Young SW et al. US-guided renal transplant biopsy: efficacy of a cortical tangential approach. Radiology 2010; 256: $290-296$

176 Brabrand K, Midtvedt K, Gunther A et al. Color Doppler ultrasoundguided transducer compression of post biopsy bleeding of kidney transplants. J Clin Ultrasound 2013; 41: 26-31

177 Carrafiello G, D'Ambrosio A, Mangini M et al. Percutaneous cholecystostomy as the sole treatment in critically ill and elderly patients. Radiol Med 2012; 117: 772 - 779

178 Olsha O, Hijazi J, Goldin I et al. Vascular access in hemodialysis patients older than 80 years. J Vasc Surg 2015; 61: 177-183

179 Welch BT, Welch TJ, Maus TP. Percutaneous image-guided biopsy in an elderly population. J Vasc Interv Radiol 2010; 21: 96-100

180 Gibney RG, Fache JS, Becker CD et al. Combined surgical and radiologic intervention for complicated cholelithiasis in high-risk patients. Radiology 1987; 165: 715-719 